\title{
EFEITOS DO REVESTIMENTO DE CANAL E IMPERMEABILIZAÇÃO DO SOLO À DINÂMICA DE INUNDAÇÃO DO RIO ARROMBADOS - PE
}

\author{
Andreza Tacyana Felix CARVALHO'; Osvaldo Girão da SILVA²; Jaime Joaquim da Silva \\ Pereira CABRAL ${ }^{3}$
}

(1) Geógrafa pela Universidade Federal de Pernambuco, Mestre e Doutoranda em Recursos Hídricos pelo Programa de Posgraduação em Engenharia Civil da Universidade Federal de Pernambuco. Endereço: Rua Santana, 367, Casa Forte, Recife - Pernambuco - CEP 52060-460. Endereço eletrônico: andreza.recursoshidricos@gmail.com.

(2) Professor Adjunto do Departamento de Ciências Geográficas da Universidade Federal de Pernambuco. Endereço: Universidade Federal de Pernambuco - Centro de Filosofia e Ciências Humanas, Av. Acadêmico Hélio Ramos, S/N, $6^{\circ}$ andar, sala 604, Cidade Universitária, Recife - Pernambuco - CEP: 50740-520. Endereço eletrônico: osgirao@ gmail.com.

(3) Professor Titular do Departamento de Engenharia Civil da Universidade Federal de Pernambuco. Endereço: Universidade Federal de Pernambuco, Centro de Tecnologia de Geociências, Rua Acadêmico Hélio Ramos, S/N, Cidade Universitária - Recife Pernambuco - CEP 50740-530. Endereço eletrônico: jcabral@ufpe.br.

\author{
Introdução \\ Materiais e métodos \\ Área de estudo \\ Modelagem hidrodinâmica \\ Condições montadas para simulação \\ Resultados e discussão \\ Conclusão \\ Referências
}

\begin{abstract}
RESUMO - A integridade do sistema rio-planície de inundação é mantida pela alternância entre os períodos de inundação e recessão das águas assim como, pelo canal do rio e os seus compartimentos de superfície e subsuperfície. Contudo, ações de revestimento de canal associadas à ocupação do solo inclusive, da planície de inundação, podem ser responsáveis por consequências danosas à dinâmica hidrológica da bacia hidrográfica. Diante do exposto, o presente trabalho demonstra a partir de simulação computacional hidrodinâmica, tendo como área de estudo a Bacia do rio Arrombados, localizada no município do Cabo de Santo Agostinho Pernambuco - Brasil, como tais intervenções na ocorrência de chuvas intensas, neste caso, com tempos de recorrência/retorno (Tr) de 05 e 25 anos e durações (d) de 30 e 180 minutos, interferem na vazão de rios e consequentemente na dinâmica de inundação fluvial da bacia.

Palavras-chave: escoamento superficial, planície de inundação, sistema fluvial e planejamento urbano.
\end{abstract}

\begin{abstract}
The integrity of the river-floodplain system is maintained by alternating periods of flooding and recession of the waters as well as the river channel and its surface and subsurface compartments. However, channel lining of actions associated with the land use including the floodplain, may be responsible for harmful consequences to hydrological dynamics of the river basin. Given the above, this paper shows from computational simulation hydrodynamics, with the field of study of the river basin avulsions located in the municipality of Cabo de Santo Agostinho - Pernambuco - Brazil, as such interventions in the event of heavy rain, in this case, with Times recurrence / return (Tr) of 05 and 25 years and durations (d) of 30 and 180 minutes interfere with the flow of rivers and consequently in the dynamics of river flood basin.
\end{abstract}

Keywords: runoff, floodplain, river system and urban planning.

\section{INTRODUÇÃO}

A inundação ou transbordamento dos cursos d'água é um fenômeno natural da dinâmica fluvial e sua ocorrência permite que exista a conectividade hidrológica entre o canal do rio, a planície de inundação e seus compartimentos. Neste sentido, conforme cita Rocha (2011), sua periodicidade de ocorrência está associada originalmente com o regime climático ou hidrológico particular de cada bacia hidrográfica.

Ainda, como menciona Paz et al. (2010), durante a maior parte do tempo, nas épocas de estiagem e de chuvas moderadas, o escoamento superficial da bacia está limitado ao canal principal do rio e é predominantemente unidimensional na direção do curso d'água. Já em períodos de chuvas intensas, ocorre prontamente o aumento do nível da água acima das margens do canal e o transbordamento do escoamento para a planície.

No entanto, a falta de planejamento e de controle do uso do solo pode ser responsável por consequências danosas à dinâmica hidrológica da bacia hidrográfica. Verifica-se que no processo da ocupação urbana brasileira, os cursos d'água ainda são poucos considerados ou até mesmo negligenciados no ordenamento territorial. E que, o incremento do escoamento 
superficial originado pela impermeabilização é basicamente disposto aos projetos clássicos de drenagem urbana.

Segundo Fraga (2013), a visão tradicional e imediatista do planejamento urbano ainda impera nos órgãos técnicos e na população em geral; para ambos, as águas pluviais não são vistas como fonte exclusiva de manutenção natural dos recursos hídricos e ações urbanossociais não são responsáveis pela origem dos problemas.

Sobre essa problemática, Yannopoulos et al. (2013) e Maus et al. (2013) destacam que o processo intensivo e expansivo da urbanização contribui para gradativa diminuição da capacidade de infiltração nas áreas urbanas, provocando alterações significativas nas características do hidrograma de enchente (aumento do fluxo de pico e volumes de escoamento e, diminuição no tempo de concentração da bacia).

Haja à vista o fato, Tucci (2015) corrobora que para resolver este tipo de problema, o poder público por diversas vezes investe somas consideráveis de recursos em obras de canalização/revestimento de cursos d'água, que na realidade tendem a agravar o problema pela amplificação para jusante das vazões máximas. Assim, Lima \& Righetto (2011) destacam que, a magnitude e as consequentes inundações provocadas pelas atuais ocorrências dos eventos hidrológicos explicitam, não somente, o despreparo social para enfrentar tais ocorrências, mas também a falta de comprometimento com o correto processo de ordenação urbana e territorial sob o ponto de vista de gestão e gerenciamento do crescimento desses espaços.

Além disso, Freitas et al (2011) direcionam que obras como estas, afetam diretamente na troca hídrica entre os interstícios dos bancos de sedimentos das margens e do leito dos corpos d'água superficiais com os aquíferos, bem como, no transporte de matéria orgânica e de oxigênio e, na atividade microbiana. Neste caso, como reforçam Santos e Pinheiro (2002), os revestimentos modificam inclusive as relações hidrodinâmicas entre as vias de interação das zonas ripária e hiporreica do curso d'água e o aumento da velocidade de escoamento.

Sendo assim, com objetivo de simular/prever os efeitos de intervenções como estas, ao meio ambiente, foram criados os modelos computacionais hidrológicos e/ou hidrodinâmicos, que segundo D'Alterio (2004) permitem a simulação de condições de escoamento baseadas na formulação e soluções de relações matemáticas que expressam princípios hidráulicos conhecidos. Ainda sobre isto, Fraga (2013) cita que, através desses modelos é possível avaliar o comportamento e a distribuição da água em um sistema, dentre outras particularidades do escoamento, o que possibilita efetuar previsões e comparações de forma simplificada do fenômeno físico que se deseja representar.

Diante do exposto, este trabalho utiliza-se do Modelo Matemático de Células de Escoamento para bacias urbanas - MODCEL desenvolvido por Miguez (2001), para demonstrar os níveis de inundações e incremento de vazão no curso d'água em períodos de chuvas intensas devido à ocupação do solo e o revestimento da calha fluvial; tendo como área de estudo, a Bacia do rio Arrombados localizado no município do Cabo de Santo Agostinho - Pernambuco Brasil.

\section{Área de estudo}

A bacia hidrográfica do rio Arrombados é uma bacia costeira, pertencente ao Grupo de Bacias de Pequenos Rios Litorâneos (GL2). Está inserida na Região Metropolitana do Recife - RMR sob as coordenadas UTM $9080000 \mathrm{~m} \mathrm{~S}$ e $9082500 \mathrm{~m} \mathrm{~S} ; 282500 \mathrm{~m} \mathrm{E}$ e $286000 \mathrm{~m} \mathrm{E}$; possui área total $2,47 \mathrm{~km}^{2}$, perímetro de $8,1 \mathrm{Km}$, densidade de drenagem segundo classificação de Horton de 0,00115 e

\section{MATERIAIS E MÉTODOS}

tempo de concentração (Tc) estimado em 56 minutos.

Originalmente é classificada como uma bacia do tipo exorreica, com drenagem consequente ou cataclinal com foz vertendo ao mar. Seu único curso d'água é o rio Arrombados, conhecido popularmente como Canal do Boto, o qual originalmente possui 3,1 $\mathrm{Km}$ de extensão, regime de escoamento perene e morfologia natural retilínea-meândrica. 
Segundo o Serviço Geológico do Brasil CPRM (2005), a bacia do rio Arrombados está sobre área de planície e terras baixas costeiras englobadas na unidade fisiográfica Litoral/Mata, onde predomina o clima quente e úmido, tipo $\mathrm{AS}^{\prime}$ de Köppen, com temperatura média anual de $25^{\circ} \mathrm{C}$ e precipitação média anual da ordem de $2.301 \mathrm{~mm}$, conforme dados do Instituto de Nacional de Pesquisas Espaciais (INPE) (2013).

De acordo com informações da Prefeitura municipal do Cabo de Santo Agostinho (PMCSA) (2008), a ocupação da bacia deu-se a partir da década de 1980 com a implantação do loteamento de Enseada dos Corais voltado a períodos de veraneio, com área total de 108.93 ha.

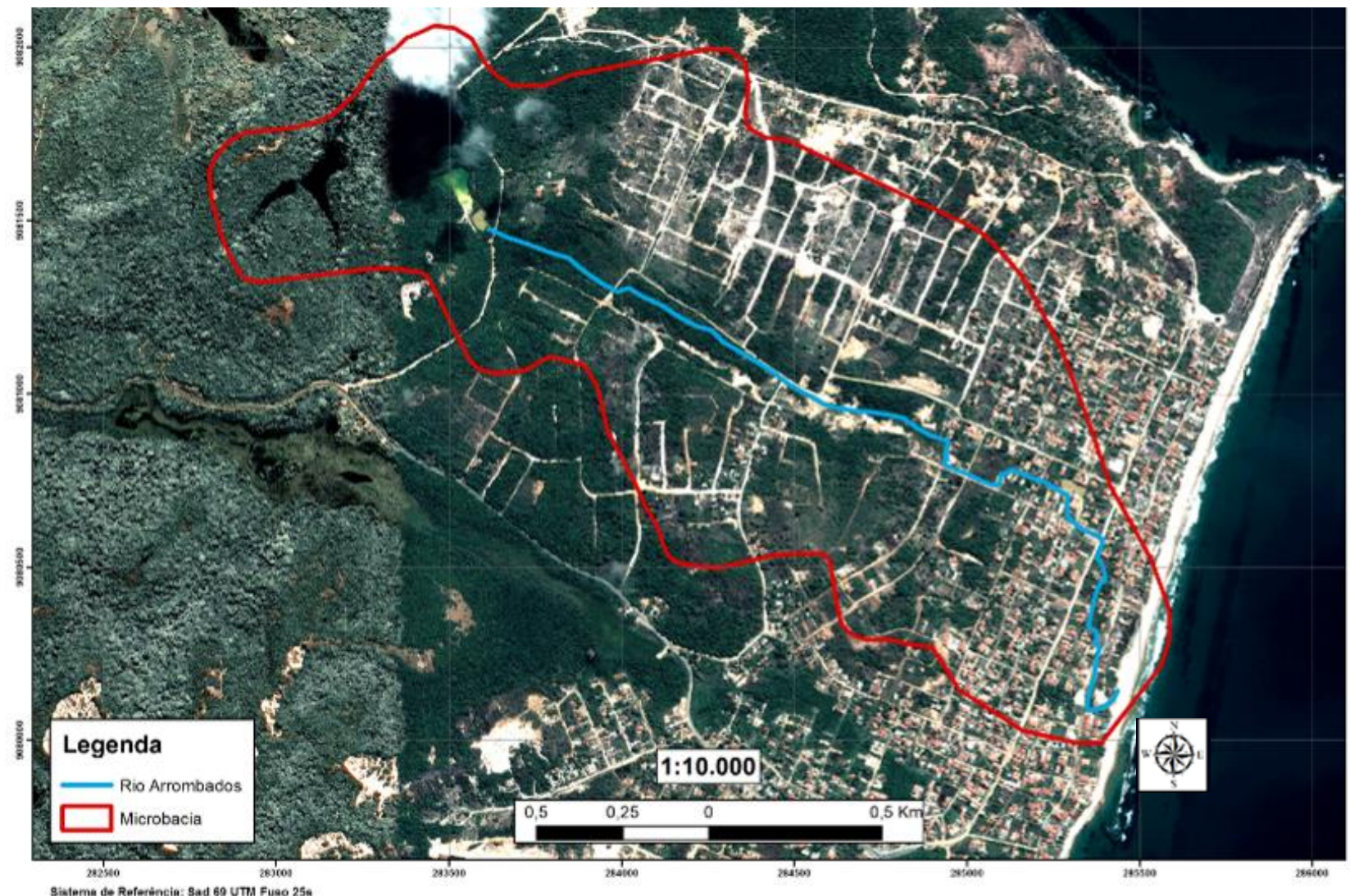

Figura 1. Ocupação e delimitação da bacia do rio Arrombados no ano de 2010 Fonte: José Paulo Santana, 2013 in Fraga (2013).

O rio Arrombados em seu baixo curso, apresenta-se revestido, com diversos pontos de estrangulamento de calha provocados por erosão e assoreamento e, com sua planície de inundação ocupada por edificações do citado loteamento (Figura 2 e 3). Em períodos de chuvas intensas, essa área da bacia sofre com as inundações, atingindo inclusive as edificações existentes (Figura 4 e 5).

Conforme a Lei Municipal $n^{\circ}$ 2.360/2006 que institui a Política Urbana e Ambiental e o
Plano Diretor do Município do Cabo de Santo Agostinho - PDU Cabo, a área total da bacia está dividida segundo zoneamento municipal em três zonas e para cada área, pré-fixado valor de Taxa de Solo Natural (TSN) a ser mantido em cada lote, sendo: Zona de Preservação Ecológica (Suape), área de $0,45 \mathrm{~km}^{2}, 100 \%$ de TSN; Zona de Expansão Residencial, área de $1,23 \mathrm{~km}^{2}, 40 \%$ de TSN e Zona Urbana Residencial III, área de $0,783 \mathrm{~km}^{2}$, também com $40 \%$ de TSN (Figura 6). 


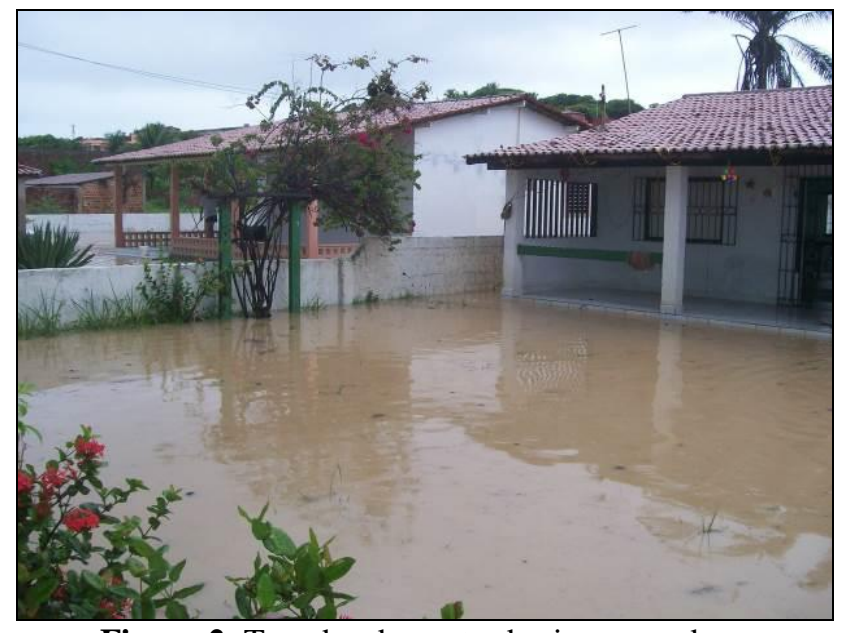

Figura 2. Transbordamento do rio causando inundação em loteamento.

Foto: PMCSA, 2008.

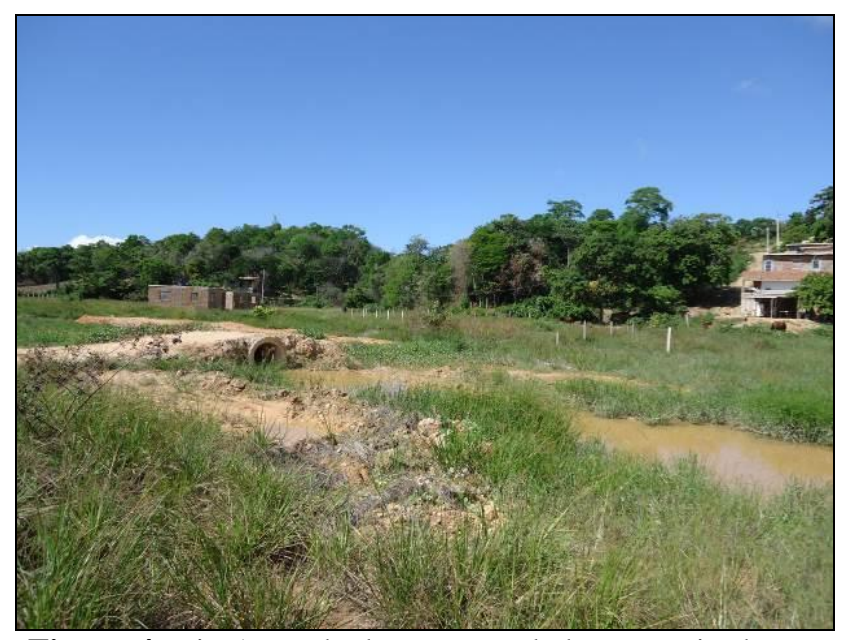

Figura 4. Rio Arrombados estrangulado por meio de manilhas

Foto: Fraga, 2013.

\section{Modelagem hidrodinâmica}

Para simulação das condições de escoamento superficial da bacia e do comportamento da dinâmica fluvial do rio em períodos de chuvas intensas, é empregado neste trabalho o programa computacional Modelo de Células de Escoamento para bacias urbanas - MODCEL, modelo hidrodinâmico desenvolvido por Miguez (2001). São utilizados como informações básicas necessárias para a modelagem matemática da bacia os seguintes dados: topográficos, hidrológicos (fluviométricos e de marés) e de uso e ocupação do solo.

Os dados topográficos foram coletados a partir da carta base do município do Cabo de Santo Agostinho do ano de 2011, com curvas de nível de $5 \mathrm{~m}$ em $5 \mathrm{~m}$ na escala 1:10.000. Quanto aos dados hidrológicos da locação do

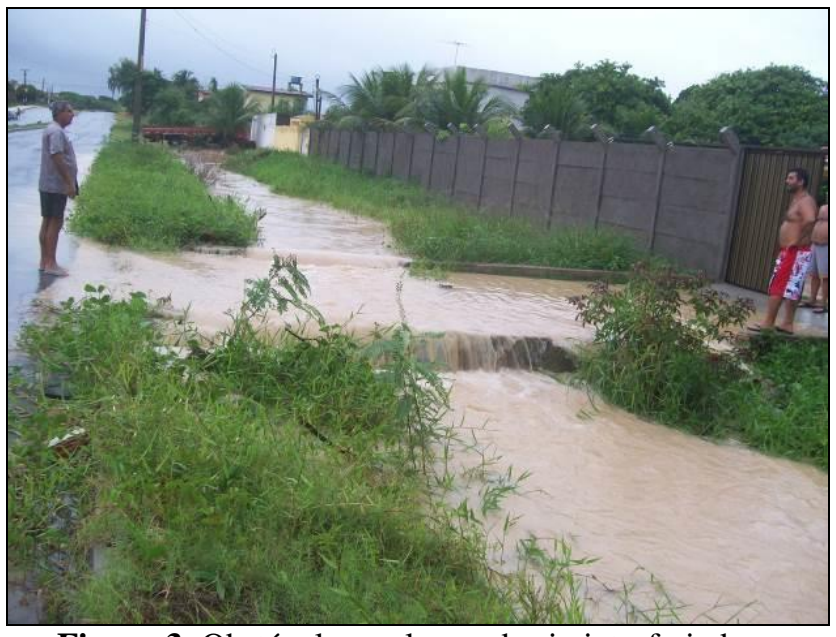

Figura 3. Obstáculos ao longo do rio interferindo diretamente em seu fluxo Foto: PMCSA, 2008.

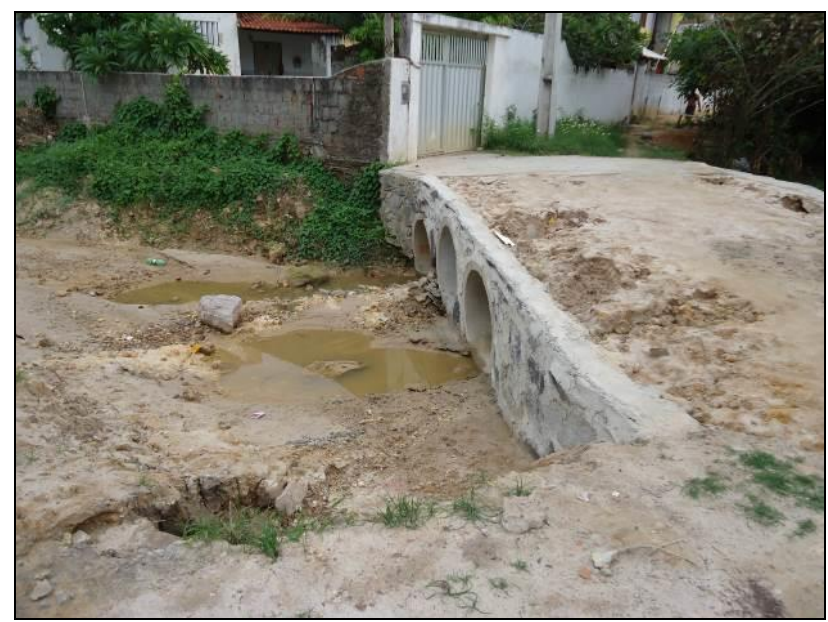

Figura 5. Ocupação urbana indevida, erosão e assoreamento interferindo no fluxo do curso Foto: Fraga, 2013.

rio existente, estes são baseados em projeto elaborado pelo órgão gestor com cadastro da área do entorno e seções transversais e, nivelamento e contranivelamento do perfil longitudinal admitindo a impermeabilização de um trecho do rio.

Com relação à ocupação da bacia, utilizamse para o reconhecimento aproximado da ocupação existente, as imagens de satélite Google Earth do ano de 2010 e as características fisiográficas da bacia através de pesquisa de campo efetuada nos dias 22 e 24 de maio de 2013, bem como, para perspectiva de ocupação futura, as definições expressas em PDU Cabo.

Desse modo, a bacia foi dividida em duas áreas: a primeira, identificada neste trabalho como Área I (restrita ao trecho do rio com calha revestida, com extensão de 1,280 Km e sua área 
de drenagem direta, identificada como Zona $\mathrm{Km}^{2}$ ) (Figura 6).

urbana residencial III com área total de 0,783

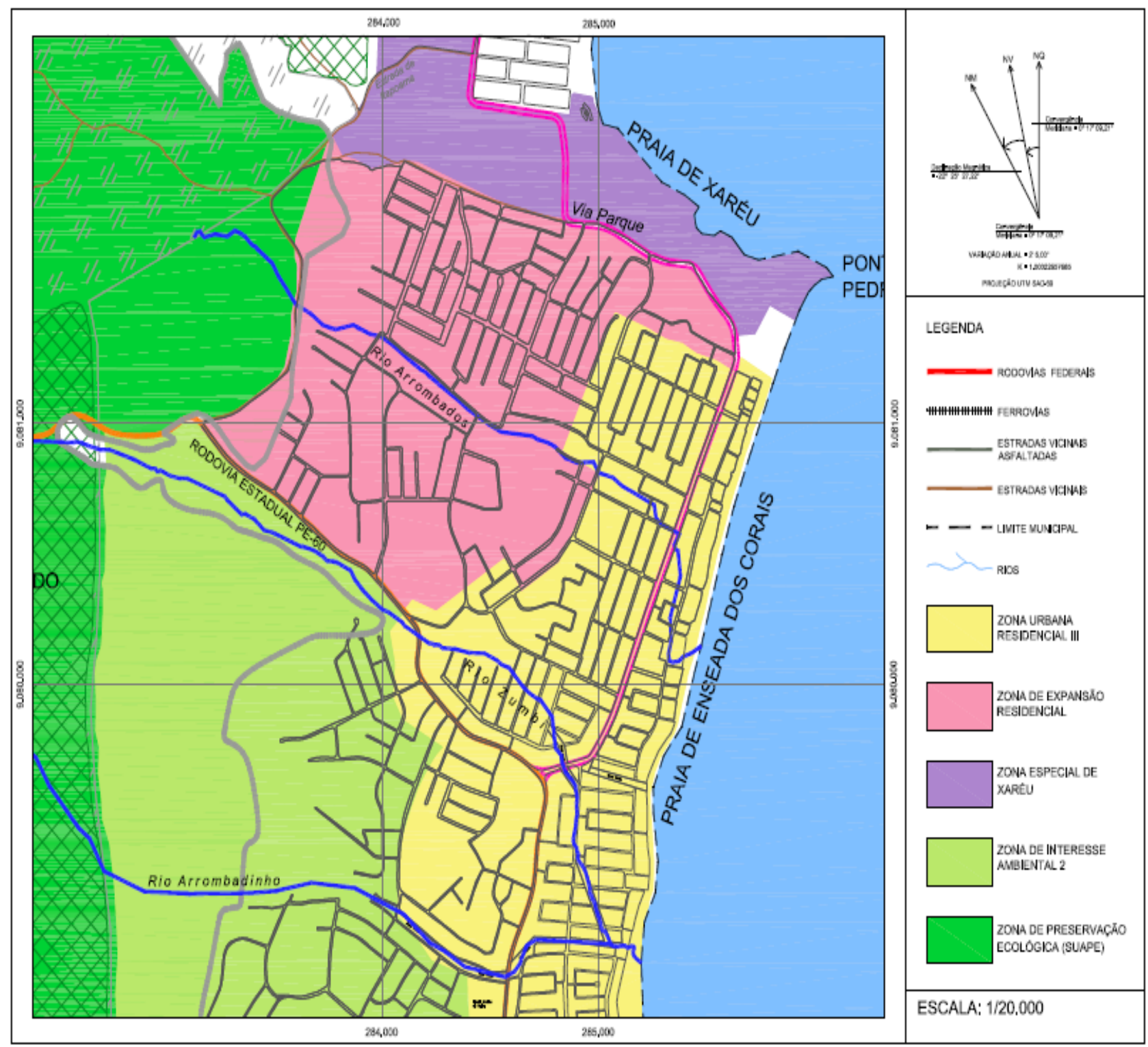

Figura 6. Região com delimitação de zonas de ocupação determinadas pelo Plano Diretor Municipal, na qual está inserida a bacia do rio Arrombados

Fonte: Fraga (2013).

Quanto a Área II, engloba a parcela da bacia com a manutenção do rio em suas condições naturais sem revestimento (aproximadamente $1,828 \mathrm{Km}$ de extensão) recebendo o escoamento da área de drenagem de $1,687 \mathrm{Km}^{2}$, referentes à Zona de Preservação Ecológica (Suape) e a Zona de Expansão Residencial (Figura 6).

Perante a insuficiência de dados de intensidade de chuva, ou seja, das séries históricas de pluviógrafos situados dentro do município do Cabo de Santo Agostinho, é adotada a entrada de dados de precipitação como chuva de projeto a partir da aplicação da Equação de chuvas intensas do município do Recife elaborada por Souza (2014) (Equação 1) e sua separação como chuva efetiva efetuada através do Programa computacional Sistema Hidro-Flu, versão 2.0 da Universidade do Rio de Janeiro (2007):

$$
i=\frac{1775,91 \times T^{0,1095}}{(t+26)^{0,8040}}
$$

Equação 1 
Onde,

$i$ - intensidade $(\mathrm{mm} / \mathrm{h})$

$T$ - Tempo de retorno (anos)

$t$ - duração (min)

Por meio dos valores de intensidade de chuva obtidos é estimado o total pluviométrico da chuva intensa para a referida área para os tempos de retorno (Tr) de 05 e 25 anos, com durações (d) 30 e 180 minutos (Tabela 1), sendo aplicado posteriormente o método racional (Equação 2), para obtenção da vazão de projeto.

Tabela 1. Total pluviométrico da chuva na bacia do rio Arrombados em mm, determinado a partir da intensidade da chuva da cidade do Recife

\begin{tabular}{r|r|r}
\hline \multirow{2}{*}{$\begin{array}{c}\text { Duração } \\
\text { (min) }\end{array}$} & \multicolumn{2}{|c|}{$\begin{array}{c}\text { Total Pluviométrico (mm) } \\
\text { da chuva da cidade do Recife }\end{array}$} \\
\cline { 2 - 3 } & $\mathbf{T r}=\mathbf{5}$ anos & Tr = 25 anos \\
\hline 30 & 41,63 & 49,65 \\
\hline 180 & 87,65 & 104,54 \\
\hline
\end{tabular}

\section{Equação 2 Condições montadas para simulação}

$$
Q=(C \times \text { i } x \text { A }) / 3,6
$$

Onde,

Q - Descarga de projeto $\left(\mathrm{m}^{3} / \mathrm{s}\right)$;

C - Coeficiente de escoamento de Run-off (adimensional);

$\mathbf{i}$ - Intensidade da chuva por um determinado tempo de duração igual ao tempo de concentração $(\mathrm{mm} / \mathrm{h})$;

A - Área da bacia de contribuição $\left(\mathrm{km}^{2}\right)$

Como trata de uma bacia em área costeira, o nível d'água das marés é considerado na simulação como uma condição de contorno em função do tempo - Z (t), sendo utilizados os dados dos dias 22 e 23 de julho de 2013 do ponto de medição da Marinha do Brasil situado no Porto de Suape - PE sob as coordenadas geográficas $8^{\circ} \quad 18^{\prime} \quad \mathrm{S} \quad$ e $34^{\circ} \quad 52^{\prime} \quad \mathrm{O}$, aproximadamente a 7,5 $\mathrm{Km}$ de distância da foz do rio Arrombados.

Assim, a partir das informações e dos dados obtidos através do trabalho de campo e da análise dos mapas, foi elaborado o seguinte esquema topológico da bacia com o arranjo representado por 61 células, subdivididos em 11 grupos (ou linhas) e duas condições de contorno (vazão de entrada gerada pela Área II e os níveis d'água da maré em função do tempo), como mostra a Figura 7.
Os cenários de simulação estão definidos dentro de dois grandes grupos, tomados como condições montadas para aplicação no modelo:

- Condição 0 - Cenário desenvolvido a partir da ocupação urbana da bacia hidrográfica existente no ano de 2010; sendo esta, desprovida de sistema convencional de microdrenagem, rio com calha revestida no trecho localizado na Área I, recebendo incremento de vazão gerado na Área II (Figuras 8 e 9).

- Condição 1 - Cenário considerando a perspectiva de ocupação urbana segundo o Plano Diretor do Município do Cabo de Santo Agostinho - Lei Municipal $\mathrm{n}^{\circ}$ 2.360/2006, com a manutenção do rio com calha revestida na Área I e recebimento do incremento de vazão gerada na Área II, a qual $1,158 \mathrm{Km}^{2}$ de sua área é destinada à expansão urbana e, o restante à manutenção da zona de preservação (Figuras 8 e 9).

Desse modo, os dados de saída de cada cenário obtidos através da simulação são agrupados e representados possibilitando efetuar interpretações sobre o incremento de vazão à planície de inundação relacionada ao revestimento de um trecho do rio Arrombados e à expansão da ocupação urbana da bacia do rio Arrombados. 


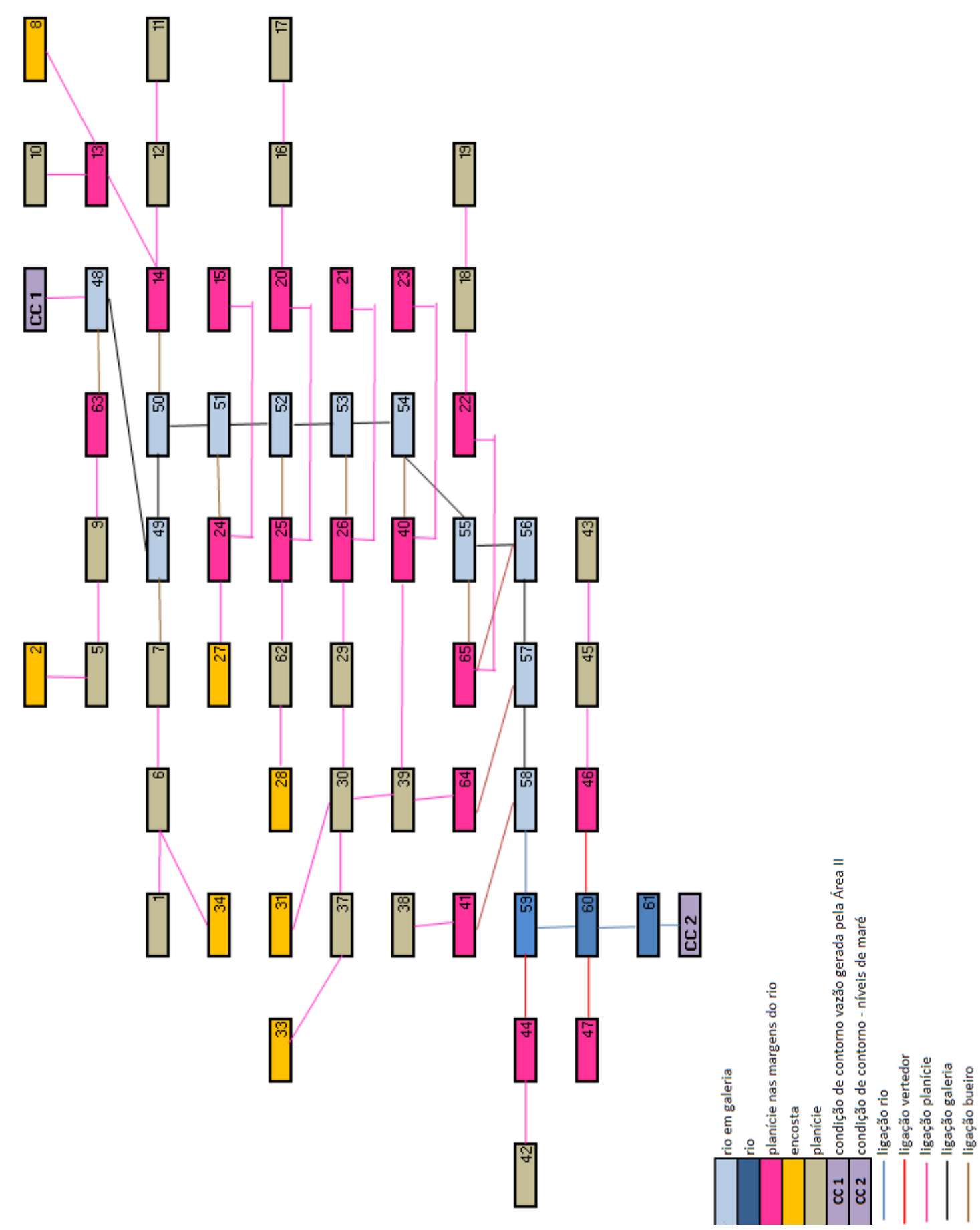

Figura 7. Esquema topológico da Área I, no baixo curso da bacia do rio Arrombados

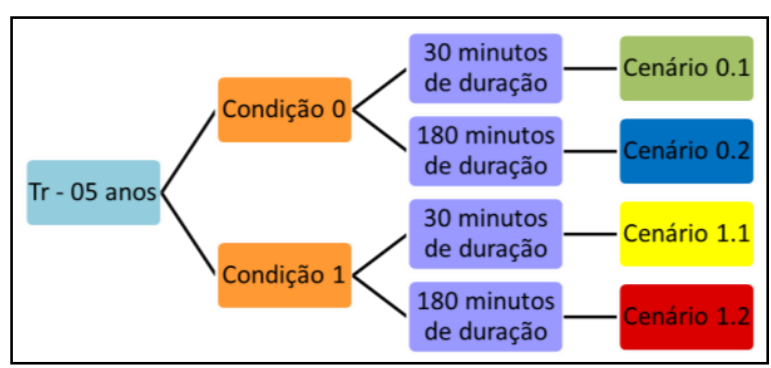

Figura 8. Cenários montados a partir do Tempo de retorno de 05 anos

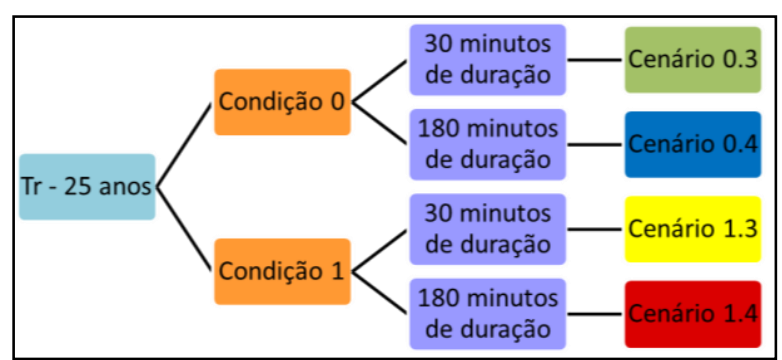

Figura 9. Cenários montados a partir do Tempo de retorno de 25 anos 


\section{RESULTADOS E DISCUSSÃO}

Inicialmente observa-se que na ocorrência do evento de chuva intensa com duração de 30 minutos para os tempos de retorno de 05 anos (cenário 0.1), as áreas margeantes do rio, já se apresentam em nível de alagamento entre $0,15 \mathrm{~m}$ e $0,7 \mathrm{~m}$, decorrente do transbordamento do rio em seu baixo curso, como mostram o Gráfico 1 e a Figura 10.

No cenário 0.2 , considera-se relevante atentar que, mesmo mantendo-se as condições existentes de ocupação do ano de 2010, a rede de hidrográfica da bacia mantida, não consegue que o escoamento gerado na ocorrência de chuva intensa com duração de 180 minutos seja comportado todo o volume pela calha definida, o que demonstra que o rio, mesmo afetado com a planície de inundação ocupada por edificações, mantém sua dinâmica de transbordamento.

Observa-se ainda através do Gráfico 1 que, o nível de água para o trecho revestido do rio, em caso de expansão urbana da bacia como prevê o PDU Cabo (Cenários 1.1 e 1.2), não deve comportar o volume de água de escoamento gerado por toda bacia. Tal fato, deve acarretar no transbordamento do rio em menor tempo, aumento de velocidade de escoamento, ampliação do nível de inundação em algumas áreas e por fỉm, criação de alagamentos em áreas antes não afetadas.

Com relação ao Gráfico 2 referente aos cenários do tempo de retorno de 25 anos, observa-se que, na existência dos cenários de ocupação urbana do ano de 2010, o rio ao receber o escoamento gerado pela bacia, atinge naturalmente por meio de transbordamento, as áreas localizadas em sua planície de inundação, como mostra a Figura 11. Percebe-se por meio desta imagem, que a bacia não possui ordenamento territorial planejado de maneira que, as áreas propícias às inundações devem estar livres de ocupações.

Além disso, como mostra ainda o Gráfico 2, após a ocupação urbana prevista para a bacia, a vazão de escoamento na mesma, independentemente do tempo de retorno e duração da precipitação, deve haver o aumento significativo de escoamento superficial na bacia, gerando o aumento da vazão do rio e, consequentemente alterando a área de inundação do mesmo. Por sua vez, somando-se a esta questão, observa-se que o revestimento da calha do rio impede a infiltração de suas águas, interferindo diretamente no processo dinâmico das vias interação, já que não as mantém livres.

Gráfico 1. Incremento de vazão ao longo do trecho revestido do rio Arrombados localizado na Área I, para o tempo de retorno de 05 anos

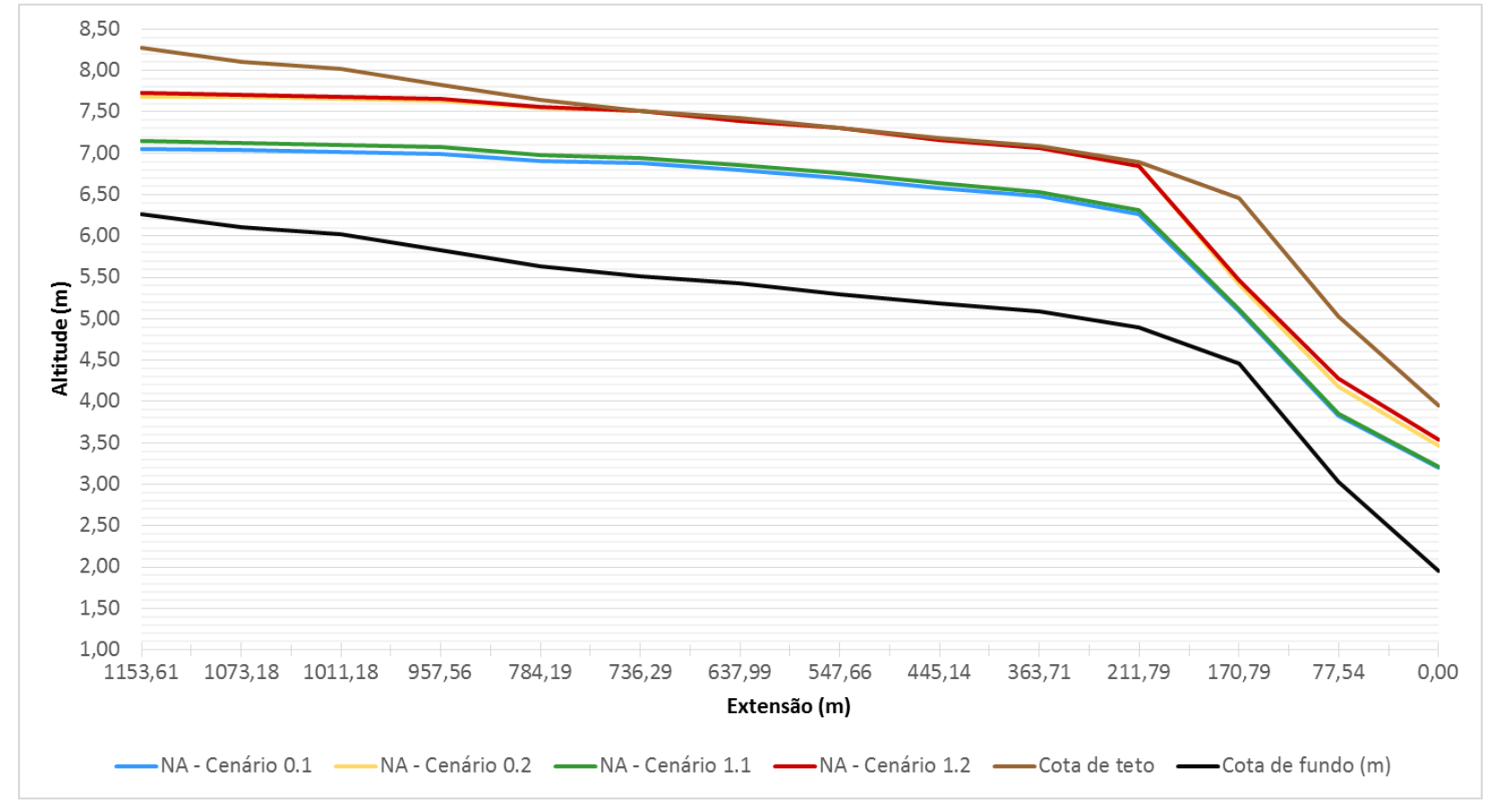




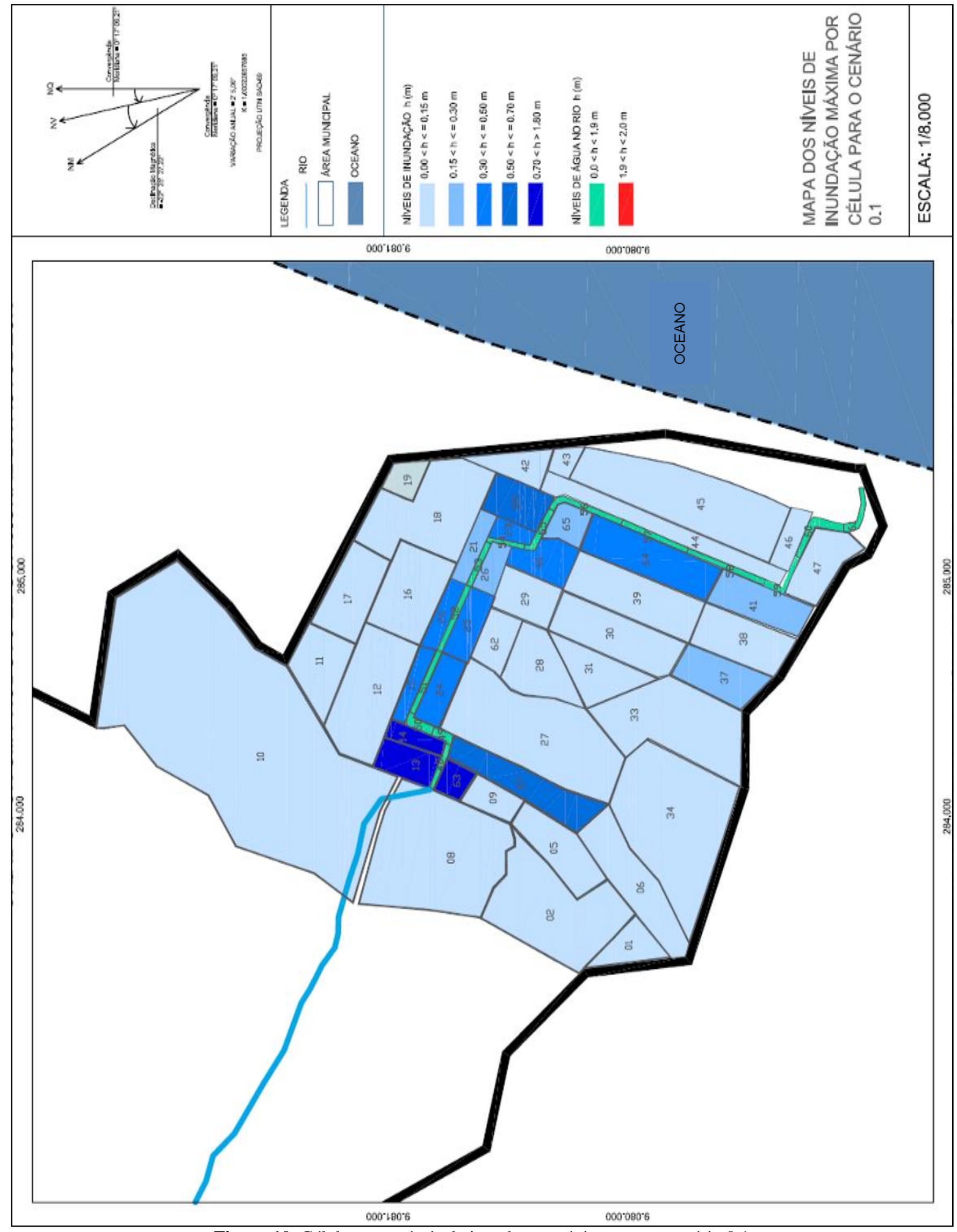

Figura 10. Células com níveis de inundação máxima para o cenário 0.1 
Gráfico 2. Incremento de vazão ao longo do trecho revestido do rio Arrombados localizado na Área I, para o tempo de retorno de 25 anos

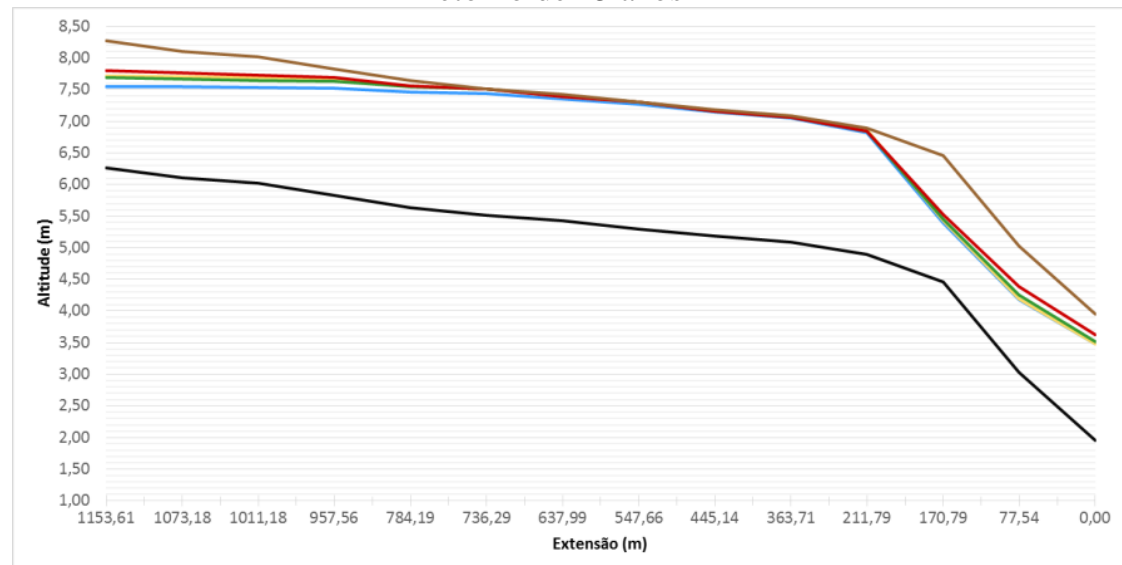

—NA-Cenário 0.3 - NA - Cenário 0.4 — NA - Cenário 1.3 — NA-Cenário 1.4 — Cota de teto —Cota de fundo (m)

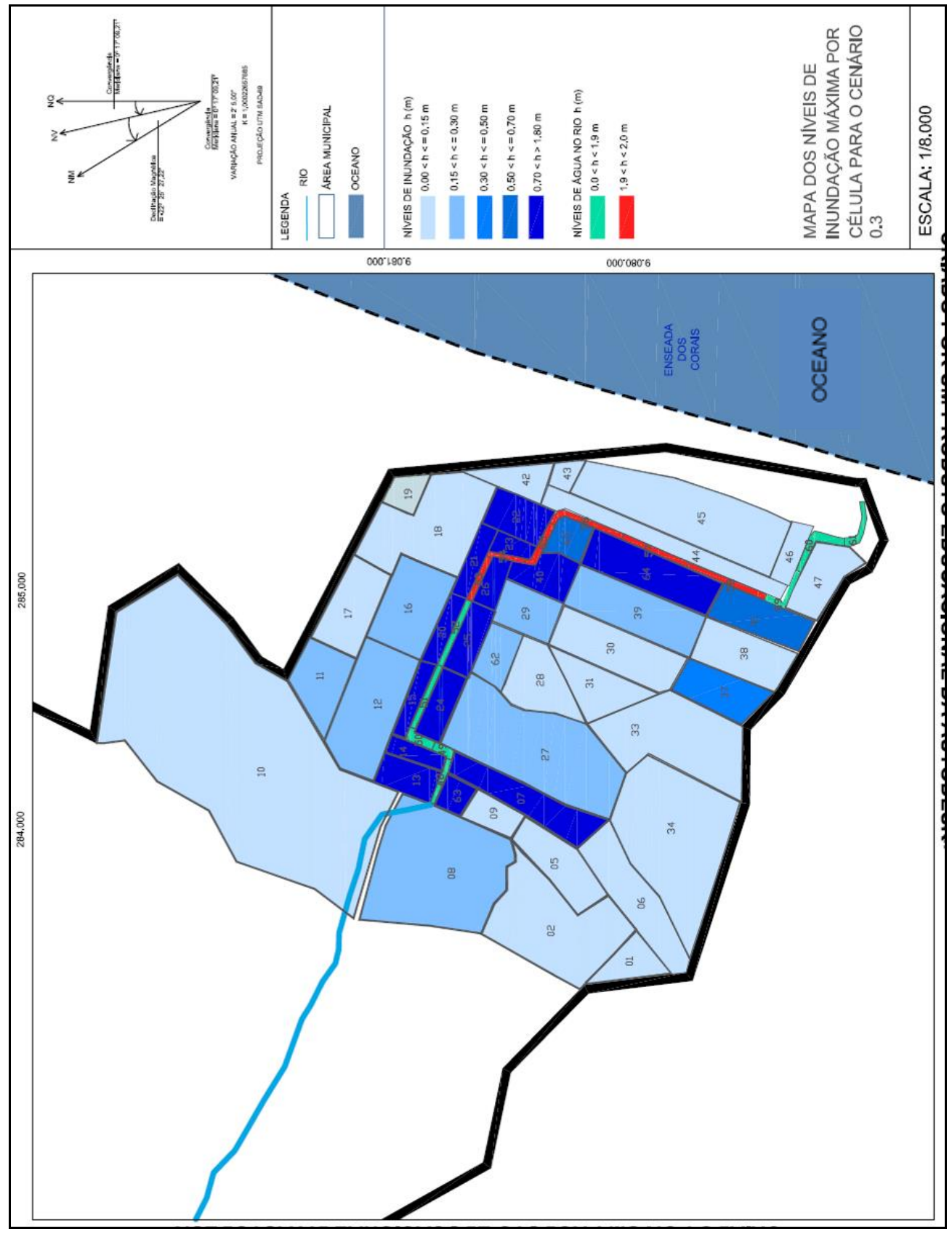

Figura 11. Células com níveis da mancha de inundação máxima para o cenário 0.3 
Além disso, como a vazão fluvial aumenta naturalmente de montante à jusante, com o incremento de escoamento gerado pela impermeabilização do solo e pelo tipo de geomorfologia do rio, as áreas mais próximas à foz têm maiores níveis de inundação (exceção da célula final localizada em solo arenoso em área de praia, este, com alto grau de infiltração e descarga direta no mar), como mostra a Figura 12.

Nos demais cenários, o sistema hidrográfico trabalha de forma crítica e diversos pontos de inundações são formados, afetando as edificações existentes na parte mais bacia da bacia (exceto a área de praia) como mostram as Figuras 11 e 12.

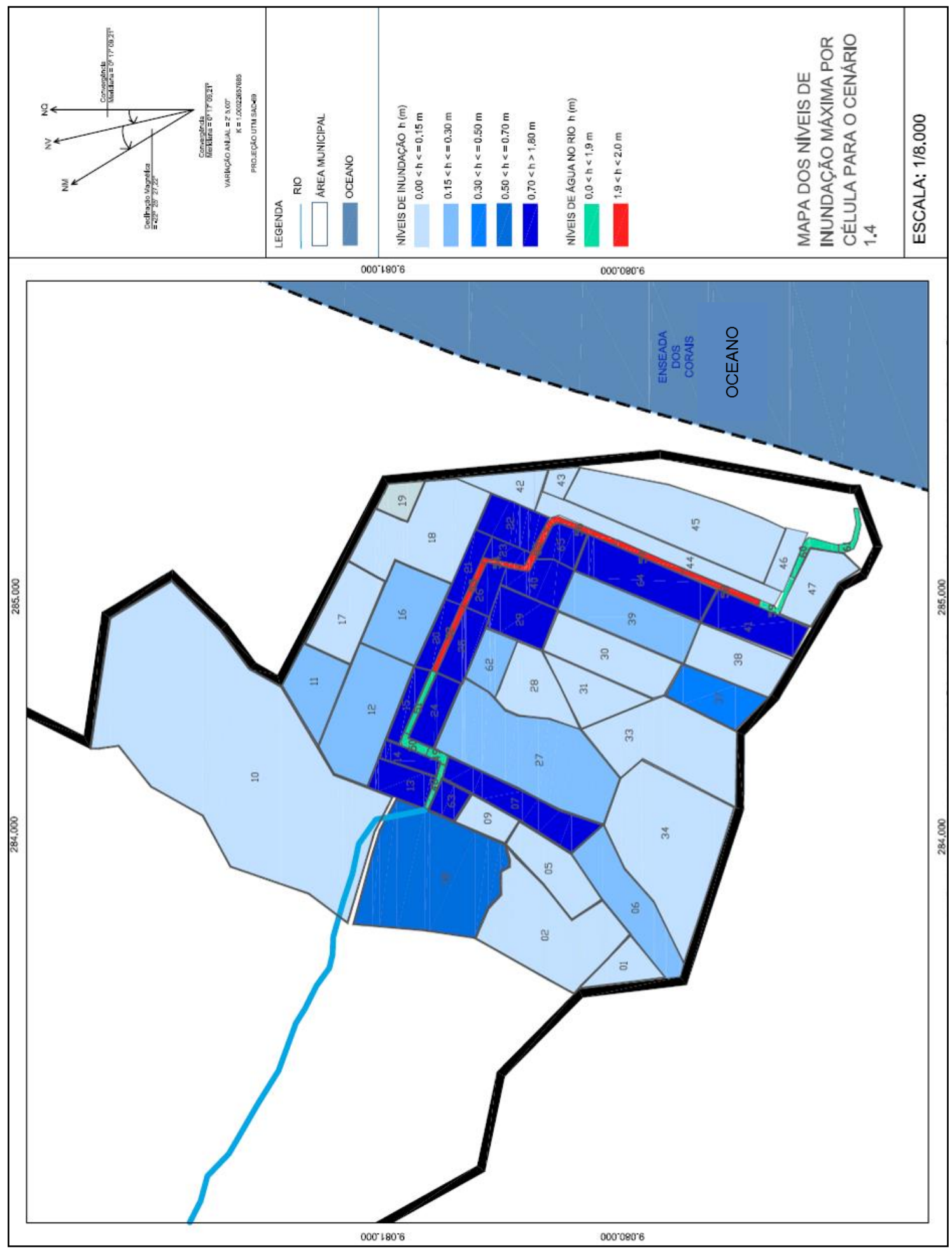

Figura 12. Células com níveis da mancha de inundação máxima para o cenário 1.4 


\section{CONCLUSÃO}

Observa-se que os cursos d'água frequentemente deixam de ser considerados como elementos estruturadores principais do ordenamento territorial, sendo, por muitas vezes, revestidos e retificados, com o leito e margens dispostos e ocupados por edificações como se fossem compartimentos isolados, comprometendo as interações hidrológicas e também biológicas do sistema interflúvio-fundo do vale.

Ações de revestimento e retificação de canais levam à modificações na calha do rio e consequentemente impactos ao canal e planície de inundação, sendo comum o desencadeamento de mudanças no padrão de drenagem, reduzindo o comprimento do canal pós alargamento, aprofundamento e retificação, diminuição de rugosidades do leito e aumento do gradiente. Com relação à impermeabilização das margens e interflúvios, esta reduz ou inviabiliza, espaços naturais ao escoamento de vazão das enchentes nas margens e planície aluvial, minimiza o processo de infiltração das águas pluviais, com o consequente aumento e aceleração do escoamento superficial e, por conseguinte, aumento da vazão e dos picos destas, principalmente à jusante de trechos retificados e impermeabilizados.

A simulação desenvolvida permitiu observar a dinâmica fluvial de uma bacia hidrográfica em processo de expansão urbana conforme definição de seu planejamento urbano, a partir da composição de cenários considerando inclusive as consequências do revestimento de um trecho do único rio da bacia e a ocupação urbana da área de planície de inundação. Sendo assim, foi possível demonstrar que as inundações nas áreas marginais são intensificadas devido aos fatores intervenientes ao processo de urbanização aplicado.

Perante a problemática, toma-se como recomendação que, o tipo de canal quanto aos aspectos de forma e função devem ser considerados no processo de planejamento do meio urbano, bem como, faz-se necessário que os profissionais que trabalham direta e indiretamente no ramo apropriem-se não apenas do conhecimento, mas que atuem de maneira a aceitar e planejar os espaços respeitando a natureza dos cursos d'água, bem como atuem de forma integrada e multidisciplinar.

E por fim, que a sensibilidade ambiental por meio de práticas sustentáveis com relação às ocupações urbanas possa ser objeto de ações de todas as esferas governamentais, contribuindo de maneira importante na composição de novos cenários urbanos, garantindo inclusive, a conservação dos corpos hídricos.

\section{REFERÊNCIAS}

1. D’AltÉRIO, C. F. V. Metodologia de cenários combinados para controle de cehias urbanas com aplicação à bacia do rio Joana. Rio de Janeiro, 2004. 240p. Dissertação (Mestrado em Engenharia Civil) Departamento de Engenharia Civil, Universidade Federal do Rio de Janeiro: Rio de Janeiro, RJ. 240p.

2. FRAGA, A. T. F. C. Interrelação entre o planejamento urbano, ocupação do solo e problemas de drenagem de águas pluviais na Bacia do Rio Arrombados (Cabo-PE). Recife, 2013. 200p. Dissertação (Mestrado em Engenharia Civil) Departamento em Engenharia Civil, Universidade Federal de Pernambuco.

3. FREITAS, D. A. de; CABRAL, J. J. da S. P.; PAIVA, A. L. R. de; VERAS, T. B. Influência da zona ripária e da zona hiporreica na interação dos aquíferos com os manancias de superfícies. In: XIX SIMPÓSIO BRASILEIRO DE RECURSOS HÍDRICOS, 19, 2011, Maceió. Porto Alegre: Associação Brasileira de Recursos Hídricos, 2011. 16p.
4. INSTITUTO NACIONAL DE PESQUISAS ESPACIAIS. Previsão do tempo e eventos climáticos. Disponível em http://tempo.cptec.inpe.br/. Acesso em 20 de dezembro de 2014.

5. LIMA, R. R. M. de; RIGHETTO, A. M. Modelagem hidrológica em bacias urbanas com nível de discretização de lotes e quadras. XIX SIMPÓSIO BRASILEIRO DE RECURSOS HÍDRICOS, 19, 2011, Maceió. Porto Alegre: Associação Brasileira de Recursos Hídricos, 2011. 14p.

6. MAUS, V. W.; RIGHES, A. A. \& BURIOL, G. A. Pavimentos permeáveis e escoamento superficial da água em áreas urbanas. In: I SIMPÓSIO DE RECURSOS HÍDRICOS DO NORTE E CENTROOESTE, 1, 2007, Cuiabá. Porto Alegre: Associação Brasileira de Recursos Hídricos, 2007, 8p.

7. MIGUEZ, M. G. Modelo matemático de células de escoamento para bacias urbanas. Rio de Janeiro, 2001. 310p. Tese (Doutorado em Engenharia Civil) Departamento de Engenharia Civil, Universidade Federal do Rio de Janeiro, Rio de Janeiro, RJ. 310p 
8. MigueZ, M. G., MASCARELHAS, F. C. B. \& VERÓL, A. P. (2011). MODCEL: A Mathematical Model for Urban Flood simulation and integrated flood control design. Acqua e Città , v. 4. p. 1- 17, 2011. 9. PAZ, A. R. da; COLLISCHONN, W.; TUCCI, C. E. M. Simulação hidrológica de rios com grandes planícies de inundação. Revista Brasileira de Recursos Hídricos. V. 15, n.4, Out/Dez, p. 31 - 43, 2010.

10. PREFEITURA MUNICIPAL DO CABO DE SANTO AGOSTINHO (2008) - Estudo hidrológico e projeto executivo do canal da Praia do Boto, loteamento Enseada dos Corais, município do Cabo de Santo Agostinho, Estado de Pernambuco. 75p., Prefeitura do Cabo de Santo Agostinho, Cabo de Santo Agostinho, PE, Brasil.

11. PREFEITURA MUNICIPAL DO CABO DE SANTO AGOSTINHO. Lei $\mathbf{n}^{\mathbf{0}} \mathbf{2 . 3 6 0}$, de 29 de Dezembro de 2006: Política Urbana e Ambiental e o Plano Diretor de Desenvolvimento Urbano e Ambiental do Cabo de Santo Agostinho. Cabo de Santo Agostinho, 2012.

12. ROCHA, P. C. Sistemas rio-planície de inundação: geomorfologia e conectividade hidrodinâmica. Caderno Prudentino de Geografia, n.33, v.1, jan./jul, p.50-67, 2011.

13. SANTOS, G. F. dos; PINHEIRO, A. Transformações geomorfológicas e fluviais decorrentes da canalização do rio Itajaí-Açu na divisa dos municípios de Blumenau e Gaspar (SC). Revista Brasileira de Geomorfologia, Ano 3, n. 1. p. 1-9, 2002.

14. SERVIÇO GEOLÓGICO DO BRASIL - CPRM. Diagnóstico do município do Cabo de Santo Agostinho. Recife: CPRM/PRODEEM, 20p, 2005.

15. SOUZA, J. C. B. de. A influência do método de escolha do parâmetro " $C$ " na determinação de equações de chuvas intensas. Recife, 2013. 230p. Dissertação (Mestrado em Engenharia Civil) Departamento de Engenharia Civil, Universidade Federal de Pernambuco.

16. TUCCI, C. E. M. Elementos para o controle da drenagem urbana. Disponível em: www.semarh.se.gov.br. Acesso em 02 de janeiro de 2015. p.1-10.

17. UNIVERSIDADE FEDERAL DO RIO DE JANEIRO. Sistema Hidro-Flu, versão 2.0. Rio de Janeiro: Universidade do Rio de Janeiro, 2007.

18. YANNOPOULOS, S. I.; GRIVAKI, G.; GIANNOPOULOU, Io.; BASBAS, S.; OIKONOMOU, E. K. Environmental impacts and best management of urban stormwater runoff: measures and legislative framework. Global NEST Journal, v. 20, n. 10, p. 1 - 9, 2013. 